\title{
Docosahexaenoic Acid Promotes Photoreceptor Differentiation without Altering Crx Expression
}

\author{
Andrés Garelli, Nora P. Rotstein, and Luis E. Politi
}

Purpose. The precise molecular cues required for photoreceptor development are still unknown. Pax6 and Crx are essential during early retinal development and for photoreceptor differentiation, respectively. The lipid molecule docosahexaenoic acid (DHA) has also been shown to promote photoreceptor differentiation. Pax6 expression during the early steps in photoreceptor development and whether the mutual contribution of Crx and DHA enhances photoreceptor differentiation were investigated.

Methods. Neuroblast proliferation, Crx, and Pax6 expression were investigated in rat retinas in vivo and in neuronal cultures with or without DHA. BrdU incorporation, nestin and opsin expression, apical differentiation, and axonal outgrowth were determined by phase microscopy and immunochemistry.

Results. Pax6 expression occurred in all proliferating retinal neuroblasts in vivo; however, after their last mitotic division, photoreceptors stopped expressing Pax6 and started expressing Crx. In vitro, photoreceptor progenitors also showed a switch from Pax6 to Crx expression immediately after they exited the cell cycle and started differentiation. In contrast, those progenitors differentiating into amacrine neurons continued expressing Pax6 and did not express Crx. Most postmitotic photoreceptors expressing Crx showed little axon development and few of them expressed opsin. The addition of DHA dramatically increased differentiation in Crx-positive photoreceptors, enhancing opsin expression, apical differentiation, and axonal outgrowth, without affecting Crx expression.

Conclusions. The results suggest that Pax 6 and Crx expression are mutually exclusive during photoreceptor differentiation. Onset of Crx expression may provide a permissive stage that is essential to initiate photoreceptor differentiation, but additional support of DHA, among other environmental signals, is necessary to accomplish further differentiation. (Invest Ophthalmol Vis Sci. 2006;47:3017-3027) DOI:10.1167/iovs.05-1659

$\mathbf{R}$ od photoreceptors amount to approximately $70 \%$ of the cells in the rodent retina, ${ }^{1}$ and are, together with bipolar neurons, among the last neuronal types to achieve differentiation during retina development. Extensive research has uncovered many of the steps leading to this differentiation; however, the precise intrinsic pathways and environmental cues in-

From the Instituto de Investigaciones Bioquímicas de Bahía Blanca (INIBIBB) y Universidad Nacional del Sur (UNS), Bahía Blanca, Buenos Aires, Argentina.

Supported by grants from the National Research Council of Argentina (CONICET), FONCyT and Universidad Nacional del Sur (LEP). LEP and NPR are CONICET Research Career members, and AG is a CONICET research fellow.

Submitted for publication December 29, 2005; revised February 23 and March 8, 2006; accepted May 2, 2006.

Disclosure: A. Garelli, None; N.P. Rotstein, None; L.E. Politi, None

The publication costs of this article were defrayed in part by page charge payment. This article must therefore be marked "advertisement" in accordance with 18 U.S.C. $\$ 1734$ solely to indicate this fact.

Corresponding author: Luis E. Politi, CC 857, 8000 Bahía Blanca, Argentina; inpoliti@criba.edu.ar. volved in the regulation of this process have still to be determined. It has been established that to begin the developmental process in the eye and retina, progenitor cells must express the transcription factor Pax $6 .{ }^{2}$ Hereafter, to proceed with the development of rod photoreceptors, retinal progenitors require the combined expression of several transcription factors, including Mash1, Math3, Nrl, NeuroD, Crx, Nr2e3, and the homeobox transcription factor Otx2. ${ }^{3-5}$ Among this plethora of transcription factors, Pax6 and the cone-rod homeobox (Crx), a novel Otx-like paired-homeodomain protein, are critical for eye and photoreceptor development, respectively.

Pax6 is an eye determinant required during early development of the retina. Defects in Pax6 expression are involved in several abnormalities, including aniridia in humans, the smalleye syndrome in mice, and Peter's anomaly among others, ${ }^{2,6,7}$ whereas homozygous Pax 6 mutations cause brain defects, eye absence, and death. ${ }^{7,8}$ During early development of the eye, Pax 6 is found in all progenitors cells, playing a critical role in retina cell fate..$^{9,10}$ In the mature retina, Pax6 remains specifically localized in the inner nuclear and ganglion cell layers (INL and GCL), ${ }^{10}$ where it is thought to have important functions in amacrine, horizontal, and ganglion cells.

Crx is essential for the expression of genes associated with maturation of photoreceptors. Its upregulation appears to be a necessary step for the expression of rod photoreceptor genes. Crx binds to and transactivates photoreceptor cell-specific genes, ${ }^{11}$ including rhodopsin, interphotoreceptor retinoidbinding protein, $\beta$-phosphodiesterase, and arrestin. In the developing mouse retina, Crx is expressed as early as embryonic day (E) $12.5,{ }^{11,12}$ a time at which the first cone photoreceptors have completed their last mitotic divisions. Mutations of human Crx are associated with three retinal diseases: cone-rod degeneration (CRD), ${ }^{13}$ retinitis pigmentosa (RP), and Leber congenital amaurosis (LCA). ${ }^{13,14}$ In addition, $\mathrm{Crx}^{-1-}$ mice lack outer segments, display a reduced expression of photoreceptor-specific genes encoding rhodopsin, cone opsins, rod transducin $\alpha$-subunit, cone arrestin, and recoverin, and show flat rod and cone electroretinograms. ${ }^{15}$ In contrast, misexpression of Crx induced adult rat iris cells to express the photoreceptorspecific antigens and transcripts already described and others such as cGMP-gated channel, and NeuroD. ${ }^{16}$ As a whole, the above studies establish Crx as an important regulator of photoreceptor cell development and gene expression, whose expression is required for these cells to initiate their differentiation. However, the finding of many nonphotoreceptor cells in clones infected with virus expressing Crx suggested that Crx expression alone is not sufficient to instruct the rod cell fate. ${ }^{12}$ Hence, though the bulk of evidence indicates that Crx is indispensable for photoreceptor development and differentiation, it is still necessary to establish whether its expression is necessary and sufficient to achieve fully differentiated photoreceptors or whether other molecular cues are necessary to accomplish this purpose.

Previous work from our research group ${ }^{17-21}$ has shown that docosahexaenoic acid (DHA), the major polyunsaturated fatty acid in the retina, is essential for development and differentiation of photoreceptors. DHA is highly concentrated in rod photoreceptors, where it is crucial for modulating optimal 
visual transduction and retinal function. ${ }^{22}$ We have also demonstrated that developing photoreceptors in vitro depend on DHA to exit the cell cycle, avoid apoptosis, and proceed with their differentiation pathway. ${ }^{18,19,21,23,24}$ These findings led to the concept that DHA may act as a novel trophic factor in the retina. In addition, the effects of DHA on photoreceptor differentiation suggest that DHA may interact with Crx during development to enhance photoreceptor differentiation. Two hypotheses can be proposed: Either DHA activates Crx expression and this activation advances photoreceptor differentiation or, conversely, Crx expression provides a permissive background that allows DHA to proceed with the differentiation pathway in rod photoreceptors.

To further investigate the paths involved in photoreceptor development, we studied the changes in the expression of Pax6 and Crx in retinal neuroblasts during development in vivo and in vitro, and the mutual contribution of Crx expression and DHA to the differentiation of photoreceptor progenitors. Our results show that during development, rod photoreceptors undergo a transition from Pax6 to Crx expression. As soon as photoreceptor progenitors stop proliferating, they switch off Pax6 expression and start to express Crx. In vivo, the onset of this expression was followed by further differentiation, leading to the achievement of mature photoreceptors. However, we show that in vitro, expression of Crx in photoreceptor cells was not sufficient to promote differentiation. The additional support of DHA was necessary to advance this differentiation, without affecting Crx expression.

\section{Materials ANd Methods}

Albino Wistar rats bred in our own colony were used in all the experiments. All proceedings concerning animal use were conducted in accordance with the ARVO Statement for the Use of Animals in Ophthalmic and Vision Research.

Plastic 35-mm diameter culture dishes were purchased from Greiner bio-one (Frickenhausen, Germany). DHA was from Biomol (Plymouth Meeting, PA). Fetal bovine serum (FBS) was from Centro de Virología Animal (CEVAN, Buenos Aires, Argentina). Dulbecco's modified Eagle's Medium (DMEM) and $\mathrm{Ca}^{2+}-\mathrm{Mg}^{2+}$-free Hanks' balancedsalt solution (HBSS) was from Invitrogen-Gibco, Grand Island, NY. Trypsin, trypsin inhibitor, transferrin, hydrocortisone, putrescine, insulin, polyornithine, selenium, gentamicin, 4,6-diamidino-2-phenylindole (DAPI) and paraformaldehyde (PF) were from Sigma-Aldrich (St. Louis, MO). Bromodeoxyuridine (BrdU), secondary antibodies Alexa 488 and Alexa 594-conjugated-goat anti-mouse were from Molecular Probes (Eugene, OR); Cy3-conjugated goat anti-rabbit was from Jackson ImmunoResearch (West Grove, PA); biotin-conjugated horse antimouse and goat anti-rabbit and avidin-conjugated horseradish peroxidase were from Vector Laboratories (Burlingame, CA). Tyramide signal amplification (DuPont NEN, Wilmington, DE) was performed according to the manufacturers' instructions. For some experiments, fluorophore-conjugated tyramine compounds and reaction buffers were synthesized according to previous reports. ${ }^{25}$ Primary antibody antiSyntaxin (HPC-1) was from Sigma-Aldrich, and anti-BrdU (G3G4) and anti-nestin (rat-401) were from Developmental Studies Hybridoma Bank (developed under the auspices of the NICHD and maintained by The University of Iowa, Department of Biological Sciences, Iowa City, IA 52242). Polyclonal rabbit anti-PAX6, rabbit anti-CRX, and monoclonal anti-opsin (Rho4D2) antibodies were generous gifts of Grant S. Mastick, ${ }^{26,27}$ Cheryl M. Craft and Xuemei Zhu, ${ }^{28}$ and Robert S. Molday, ${ }^{29}$ respectively. All other reagents were of analytical grade.

\section{Embryo Collection}

Timed pregnant rats were deeply anesthetized and killed by decapitation. The day of vaginal plug observation was considered embryonic day (E) 0.5 .

\section{Tissue Cryosections}

Eyes from E20 embryos were enucleated and fixed for 3 hours in PBS-2\% paraformaldehyde at $4^{\circ} \mathrm{C}$. After lens removal, eyes were immersed in PBS-30\% sucrose until sunk, mounted in agar blocks, immersed again in PBS-sucrose overnight, frozen in liquid nitrogen, and stored at $-70^{\circ} \mathrm{C}$ until they were cut.

\section{Purified Neuronal Cultures}

Pure neuronal retinal cultures were obtained according to previously established procedures. ${ }^{30}$ However, instead of using postnatal day (P) 1 to P2 donor rats, retinas from P0 rats were used, because most photoreceptors are born at this time of development. ${ }^{31}$ In brief, the retinas were dissected and dissociated under mechanical and trypsin digestion. After dissociation, the cells were resuspended in a chemically defined medium and then seeded on 35-mm diameter dishes, sequentially pretreated with polyornithine $(0.1 \mathrm{mg} / \mathrm{mL})$ and schwannomaconditioned medium. ${ }^{32}$ Cultures were incubated at $36^{\circ} \mathrm{C}$ in a humidified atmosphere of $5 \% \mathrm{CO}_{2}$. At different times, neurons were fixed with $2 \%$ paraformaldehyde in PBS, and the number of amacrine and photoreceptor neurons, the two major cell types in the cultures, was determined. Neuronal cell types were identified by their morphology using phase-contrast microscopy and by immunocytochemistry, using the monoclonal antibodies HPC-1 and Rho4D2, which selectively recognize amacrine and photoreceptor neurons, respectively. ${ }^{29,33}$ Photoreceptors have a small round cell body $(3-5 \mu \mathrm{m})$ with a single neurite at one end, which usually ends in a conspicuous synaptic "spherule"; opsin is diffusely distributed over their cell body, which is usually darker than that of amacrine neurons. To be identified as photoreceptors, the cells had to display at least three of these criteria. Instead of a typical single axon, amacrine neurons have multiple neurites, show morphologic heterogeneity and express HPC-1 antigenicity.

\section{DHA Supplementation}

DHA was added to the cultures immediately after the cells were seeded, at a final $6.7 \mu \mathrm{M}$ concentration, in a complex with bovine serum albumin (BSA) in a 2:1-molar ratio in DMEM. The same volume and concentration of a BSA solution was added to control cultures. We have previously shown that DHA acts in a very narrow concentration range (i.e., 2-10 $\mu \mathrm{M}$ ), with higher concentrations leading to generalized neuronal death. ${ }^{17}$

\section{Antibody Labeling}

For immunocytochemical analysis of the cultures, the cells were sequentially fixed with paraformaldehyde, permeated with $0.1 \%$ Triton X-100 for 15 minutes, incubated for 30 minutes with $0.1 \%$ Tween 20 Tris buffer (TNT) with $2 \%$ skimmed milk, and then incubated with the primary and fluorescence-conjugated secondary antibodies. When tyramide amplification was used, after the primary antibody, cells were incubated with biotinylated secondary antibodies and avidin-peroxidase, as indicated by the manufacturer.

For double immunostaining with tyramide amplification, peroxidase from the first staining was inactivated with a solution of $3 \% \mathrm{H}_{2} \mathrm{O}_{2}$ and $1 \%$ azide in PBS for 25 minutes. For BrdU staining, after permeation with Triton X-100, cells were incubated for 25 minutes with $2 \mathrm{~N} \mathrm{HCl}$ for DNA denaturation, rinsed in $0.15 \mathrm{M}$ borate buffer, and then processed as indicated earlier.

Retinal sections of 8 to $12 \mu \mathrm{m}$ were mounted on silanized slides, air dried for 30 minutes, and incubated in warm PBS to remove agar, followed by fixation for 10 minutes in $2 \%$ paraformaldehyde. After permeation with Triton X-100, sections were incubated with TNT with $2 \%$ skimmed milk for 30 minutes and then overnight with the primary antibody in the same buffer. After several rinses with TNT, sections were incubated for 2 hours with the fluorescence-conjugated secondary antibody.

For BrdU and CRX antibody labeling on sections, Triton X-100 permeation was omitted, and the slides were heated in citric buffer 
Figure 1. Expression of Pax6 and Crx in retinal cells in vivo at E20. Pregnant rats were administered a single dose of BrdU at E20, and the embryos were fixed 6 hours later for immunocytochemical determinations. Retinal sections were stained with DAPI (A, D), Pax6 (B), BrdU (C, F), and Crx (E). Progenitor cells incorporated $\mathrm{BrdU}$ and migrated toward the retinal pigment epithelium, where they completed mitosis. Pax6 was expressed in progenitor cells (A-C, arrows) even during mitosis (arrow beads), whereas Crx was excluded from cycling progenitor cells (D-F, ar rowbeads). Bar, $10 \mu \mathrm{m}$.
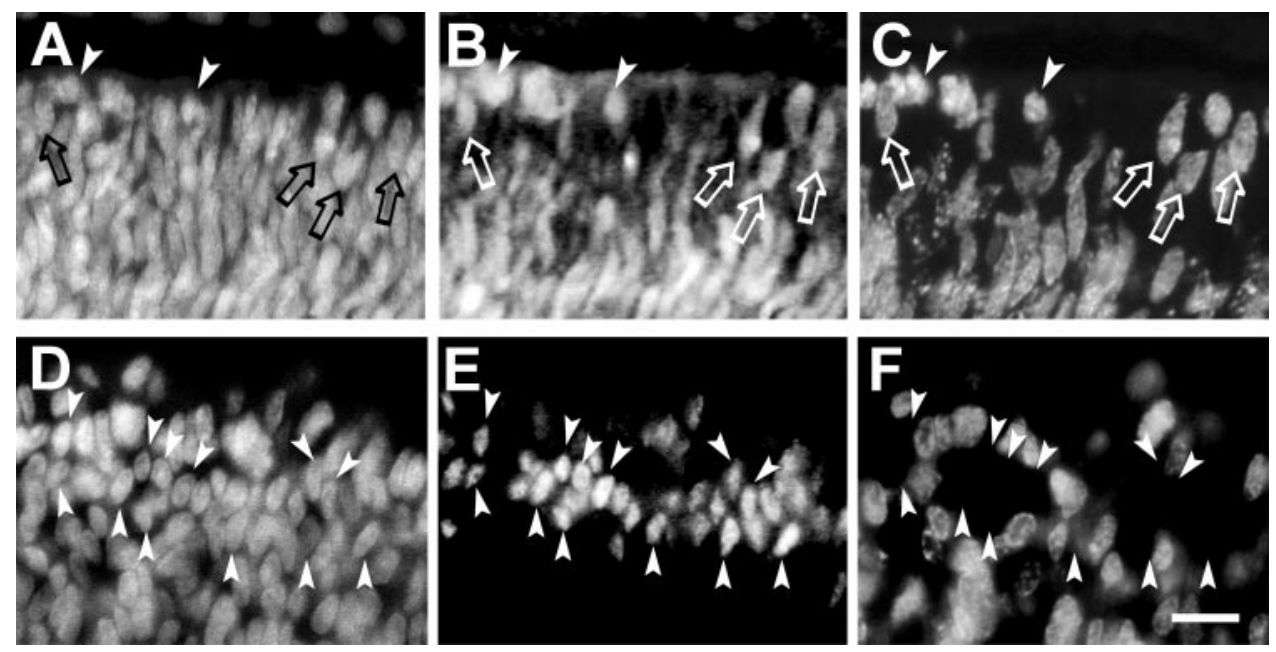

(0.1 M sodium citrate-citric acid $[\mathrm{pH} \mathrm{6}]$ ) at $95^{\circ} \mathrm{C}$ for 10 minutes to restore immunoreactivity, allowed to cool, and processed as just described. For BrdU labeling, sections were also treated with $2 \mathrm{~N} \mathrm{HCl}$ and borate buffer after heating.

For Crx labeling in cultures, cells were fixed for 30 minutes and processed as described earlier. For Rho4D2 and Crx double labeling, cells were fixed for 1.5 hours and subjected to simultaneous incubation with both primary antibodies.

\section{BrdU Injection}

For embryonic BrdU uptake experiments, pregnant rats at E20 were given a single intraperitoneal injection of BrdU (100 mg/kg). After 6 hours, embryos were collected and processed as indicated earlier. Noninjected rats were used as the control.

\section{BrdU Pulse Labeling}

To study the timing of Pax6 and Crx expression during progenitor differentiation, cultures were pulsed with BrdU at a $50 \mu \mathrm{M}$ final concentration for 4 hours at day 0 in vitro, rinsed twice with HBSS and either fixed immediately after the pulse, or cultured for an additional 1 or 2 days in chemically defined media without BrdU.

To determine the percentage of cells progressing in the cell cycle at different times in vitro, $50 \mu \mathrm{M}$ BrdU was added to cultures immediately after the cells were seeded (day 0 ) or at day 1 and 2 in culture. After 4 hours, cells were rinsed twice with HBSS and fixed.

\section{Determination of Axonal Length}

Photoreceptor cells had a short, single, and usually unbranched axon Their relative length was obtained by measuring the axonal length divided by their respective cell diameter.

\section{Statistical Analysis}

The results represent the average of three experiments ( \pm SD). Unless specifically indicated, each experiment was performed in triplicate. For cytochemical studies, 10 fields per sample were analyzed in each case. Statistical significance was determined by Student's two-tailed $t$-test.

\section{Results}

\section{Expression of Pax 6 and Crx in Retinal Progenitors}

Pax6 is expressed in all multipotent retinal progenitor cells, ${ }^{10,34,35}$ whereas expression of Crx, the earliest photoreceptor-specific gene to be expressed, ${ }^{35}$ occurs in postmitotic photoreceptors. ${ }^{36}$ To investigate the differential expression of both genes in proliferating photoreceptor progenitors at the time of their terminal mitosis, pregnant rats were injected with BrdU at E20, since most rat photoreceptors are "born" between this time and P1. ${ }^{31}$ The uptake of BrdU and its coincidence with Pax6 and Crx expression were analyzed 6 hours later (Fig. 1). As has been established, ${ }^{9,26,34,37}$ at early developmental time points, we observed that all retinal progenitor cells expressed Pax6 (not shown). At E20, many BrdU-labeled cells still occurred in the inner retina, and all of them were double labeled with Pax6. The very few BrdU-labeled cells found in the prospective outer nuclear layer were also double-labeled with Pax6 (Figs. 1B, 1C). The persistence of Pax6 expression in these cells usually accompanied the presence of mitotic figures, suggesting they might be progenitor cells, which incorporated BrdU while they were in the S phase and then migrated to this layer to complete another round of mitosis.

When double staining for BrdU uptake and Crx expression in E20 retinas was performed, numerous Crx-labeled cells were already present (Fig. 1E). However, none of the cells that expressed Crx showed uptake of BrdU (Figs. 1D-F). Similar results were obtained at PO (not shown). Hence, although BrdU-labeled cells expressed Pax6 (Figs. 1A-C), Crx expression was excluded from cycling, BrdU-labeled progenitors.

\section{Expression of Pax6 and Crx in Photoreceptors during Their Differentiation In Vivo}

We then analyzed the changes in Pax6 and Crx expression during photoreceptor differentiation in vivo. At E20, Pax6 expression extended to most progenitor cells in the retina; however, while the inner retina still expressed Pax6 (Fig. 2A), this expression was absent in a narrow line of nuclei corresponding to the prospective outer nuclear layer (Fig. 2A, large arrow). This group of Pax6-negative cells was Crx positive (Fig. 2B, large arrow), whereas no Crx expression was found in other retina layers (Fig. 2B). Expression of Crx was excluded from progenitors undergoing mitosis (Fig. 2E, small arrow), which in turn still expressed Pax6 (Fig. 2D, small arrow). Because Crx-labeled cells also excluded BrdU (Figs. 1E, 1F), these cells may be postmitotic photoreceptor precursors that have exited the cell cycle and have begun differentiation.

If the onset of Crx expression in photoreceptors was postmitotic, as more progenitors left the cell cycle to differentiate as photoreceptors, the region where Pax6 expression was replaced by Crx should widen. Specifically, the broadening of the Pax6-negative band between E20 and P0 closely matched the expansion in the Crx-expressing region (Figs. 2A, 2B, 2D, 2E). By P5, Pax6 expression completely disappeared from the outer nuclear layer (Fig. 2G), though it persisted in the inner 

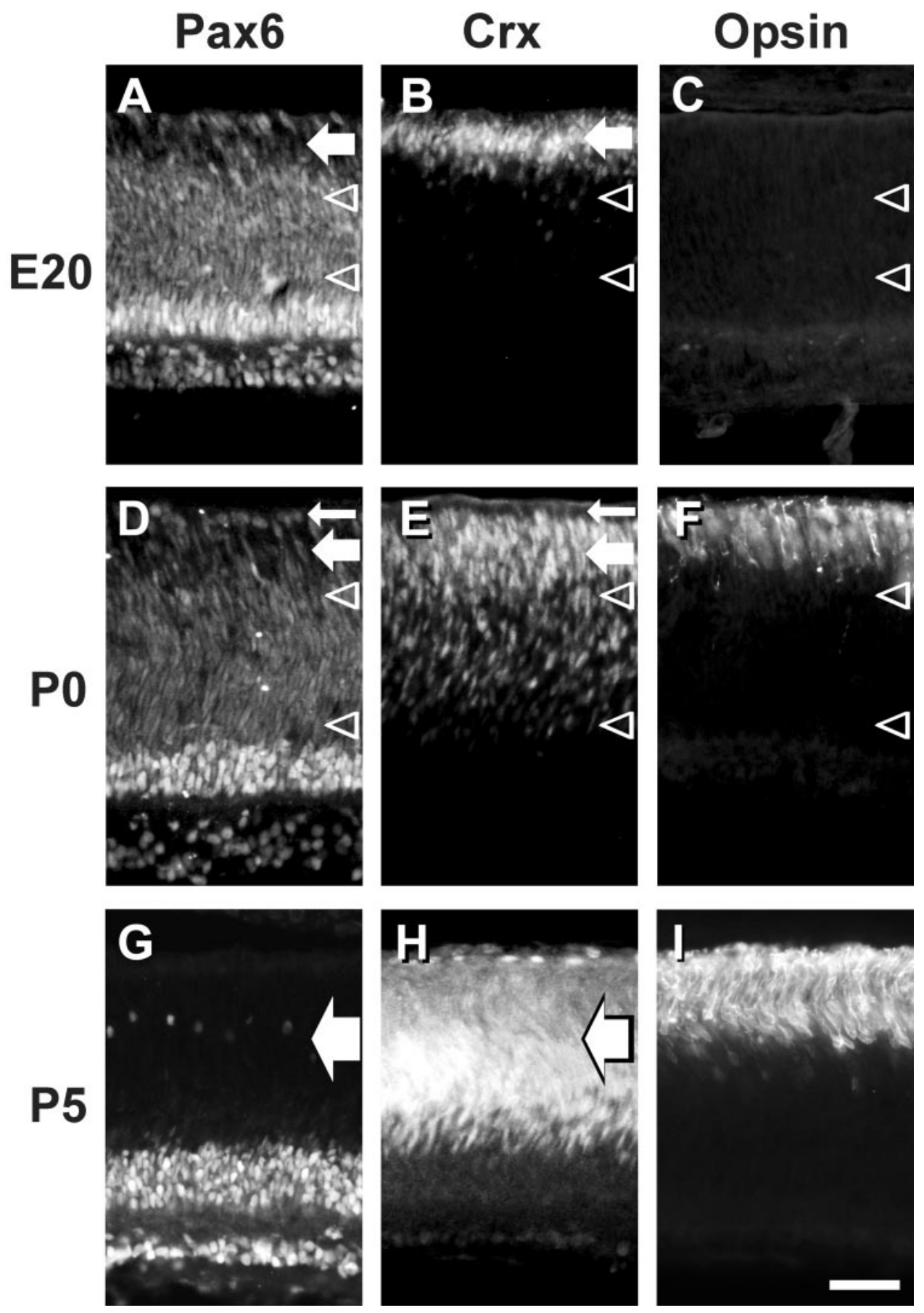

Figure 2. Pattern of Pax6, Crx, and opsin expression in the developing retina. $\operatorname{Pax} 6(\mathbf{A}, \mathbf{D}, \mathbf{G}), \operatorname{Crx}(\mathbf{B}, \mathbf{E}, \mathbf{H})$, and opsin $(\mathbf{C}, \mathbf{F}, \mathbf{I})$ immunostaining of E20 (A-C), P0 (D-F), and P5 (G-I) retinas. Pax6 was expressed in progenitor cells (region between arrowheads), except for a narrow line of nuclei that expressed Crx (A, B, large arrow). Mitotic progenitors expressed Pax6 but not Crx (small arrows, $\mathbf{D}, \mathbf{E}$ ). At $\mathrm{P} 0$, the number of Pax6-negative cells increased as did Crx expression (D, E, large arrows), until it occupied the entire outer nuclear layer at P5. These cells differentiated as photoreceptors, as indicated by opsin expression (F, I). Bar, $50 \mu \mathrm{m}$.

nuclear and ganglion cell layers (Fig. 2G). This disappearance was replaced by an intense expression of Crx in the outer nuclear layer (Fig. 2H).

Accompanying these changes, the cells that were Crx-positive at E20 and P0, began to express the visual pigment opsin at P0 (Figs. 2C, 2F), and this expression markedly increased by P5 (Fig. 2I). From this time point on, the expression of Crx and opsin was coincident in photoreceptor cells. These results suggest that the new Crx-positive cells were photoreceptor precursors undergoing differentiation.

\section{Changes in the Expression of Pax6 and Nestin in Retinal Progenitors In Vitro}

To investigate the changes in the expression of Pax6 during photoreceptor differentiation, we obtained retinal cell cultures from P0 donors. Nearly all undifferentiated cells showed a rather irregular or rounded morphology immediately after they were seeded and could be grouped as either large cells, which rapidly differentiated as amacrine neurons, or small cells, which eventually differentiated as photoreceptors, as previously described. ${ }^{23}$ Both neuronal cell types represented more than $95 \%$ of the total cells occurring in the cultures and were easily recognized by morphologic and immunocytochemical criteria. $^{23}$

In close correspondence with in vivo results, the amount of cells expressing Pax6 was higher at early culture times (Figs. 3C, 3D). Approximately $70 \%$ of mitotic cells expressed Pax 6 both 4 hours and 1 day after the cells were seeded (not shown). To establish whether these cells were multipotent progenitors, we investigated the expression of the neuroecto- 
4 hs
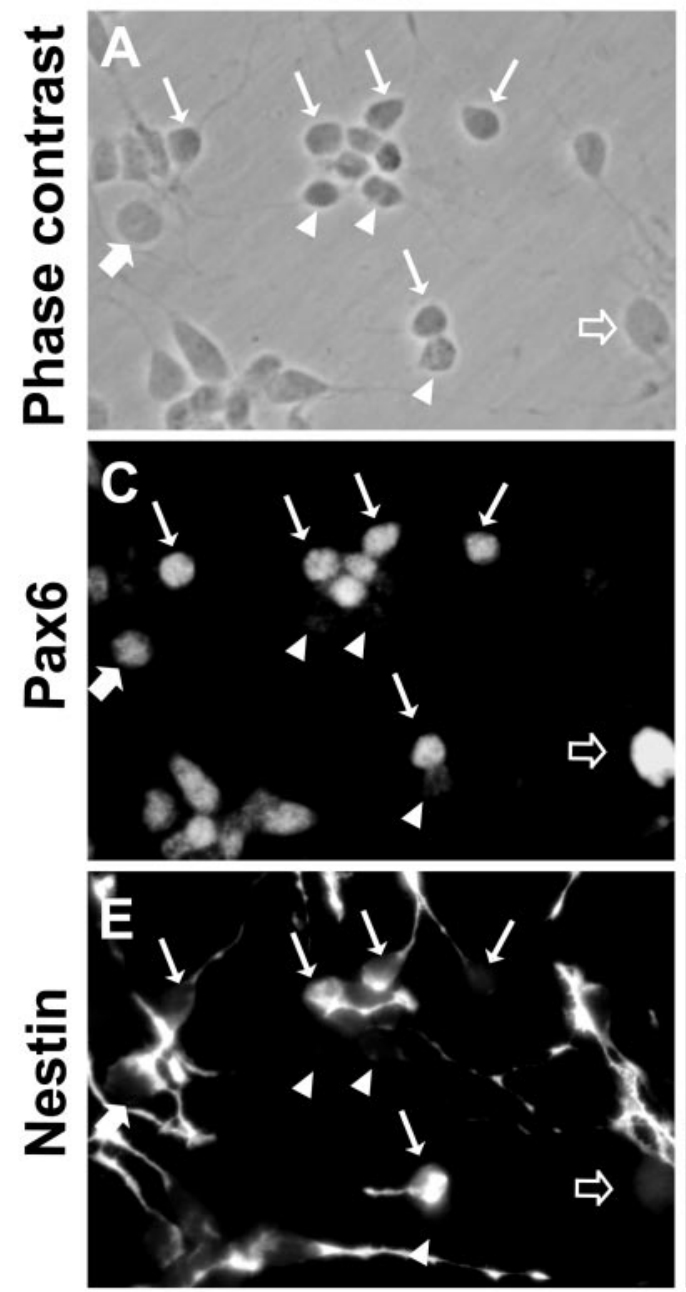

G

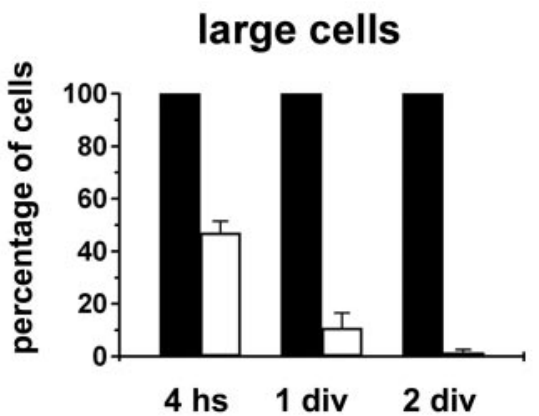

2 div
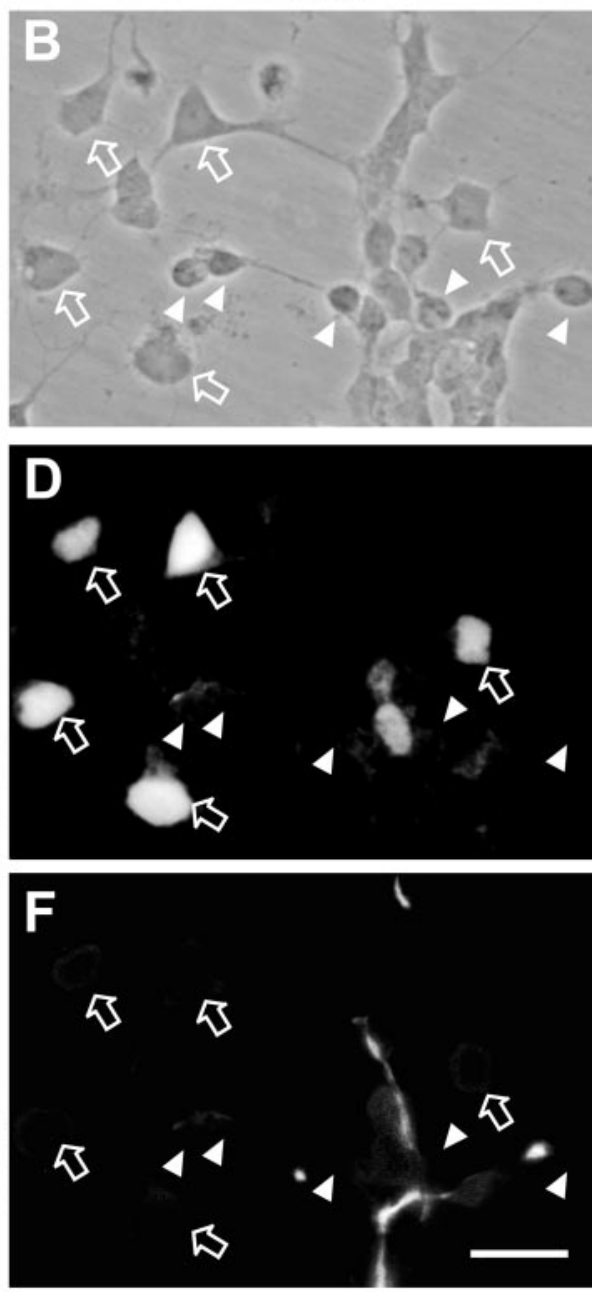

small cells

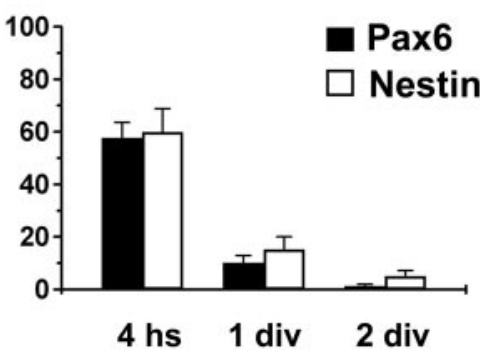

derm marker nestin, an intermediate filament that is usually expressed in cycling, multipotent progenitors in the retina. ${ }^{23}$ Most small cells coexpressed Pax 6 and nestin 4 hours after the cells were seeded (Figs. 3C, 3E; small and large filled arrows, respectively). At this time point, the same percentage of small, undifferentiated cells (approximately 60\%) were labeled with Pax6 and nestin (Fig. 3G). On the contrary, though all large cells were labeled with Pax6, only $45 \%$ of them showed nestin expression. Consistent with the reported necessity for Pax6 expression in multipotent progenitors, ${ }^{34} 97.1 \% \pm 3.9 \%(n=3)$ of the Pax6-positive mitotic cells colabeled with nestin.

The expression of both markers rapidly decreased in small cells (Figs. 3D, 3F); Pax6 (Fig. 3, arrowheads), and nestin expression (Fig. 3F) disappeared as differentiation proceeded.
By day 2, only $1 \%$ and $5 \%$ of these cells expressed Pax 6 and nestin, respectively. Disappearance of nestin expression in small cells has been shown to be parallel to an increase in opsin expression. ${ }^{23}$ In large cells, nestin expression also decreased during development and was negligible at day 2 (Fig. 3G). However, these cells retained Pax6 expression as they differentiated (Figs. 3B, 3D, open arrows); $95.9 \% \pm 2.1 \%$ of the large cells that expressed Pax6 at day 2 colabeled with HPC-1, indicating that they were differentiated amacrine cells.

Altogether, these results indicate that undifferentiated progenitors coexpressed nestin and Pax6. Once differentiated, both neuronal types lost nestin expression, and although amacrine cells retained expression of Pax6, photoreceptors no longer expressed it. 

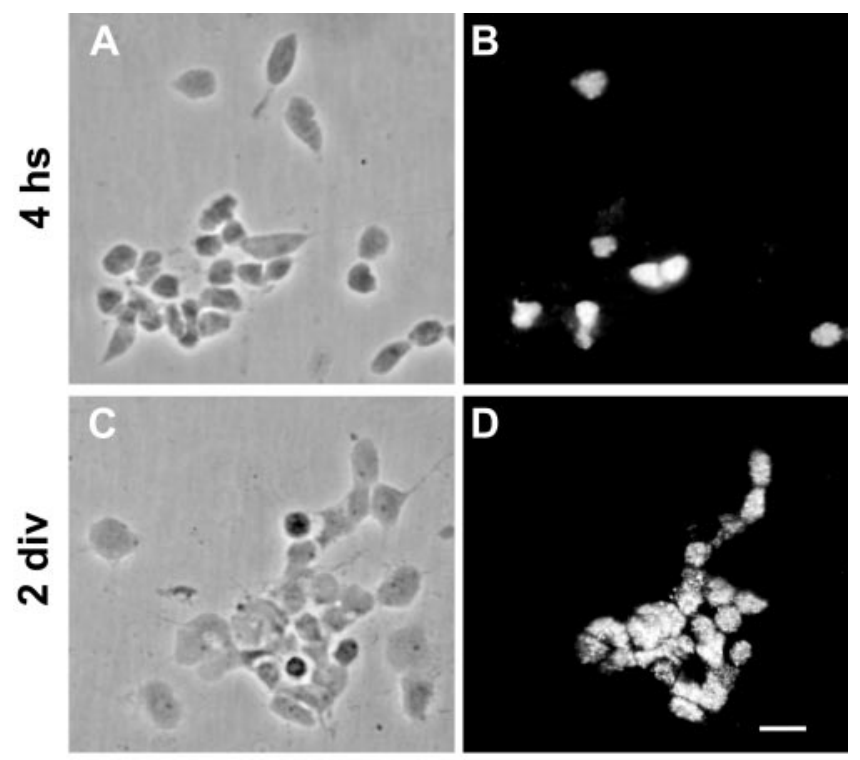

E

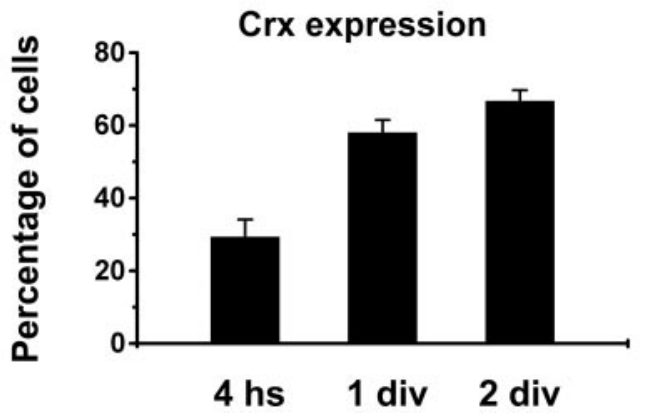

FiguRE 4. Crx expression in retinal neurons in culture. Phase contrast (A, C) and Crx staining (B, D) of retinal cell cultures after 4 hours (A, B) and 2 days $(\mathbf{C}, \mathbf{D})$ in vitro. (E) Percentage of total cells that expressed Crx at different times during their development in vitro. This percentage increased from $30 \%$ to $70 \%$ between days 0 and 2 in vitro. Bar, $10 \mu \mathrm{m}$

\section{Changes in the Expression of Pax6 and Crx during Photoreceptor Differentiation In Vitro}

To investigate further the photoreceptor differentiation process in vitro, we analyzed the pattern of Crx expression. After 4 hours of seeding the cells, almost a third of the cells expressed Crx, and this expression increased to nearly $70 \%$ of retinal neurons at day 2 (Fig. 4). This increase was consistent with the decrease in Pax6 and nestin expression in small cells (Fig. 3G).

Next, we performed BrdU pulse labeling experiments to establish whether the downregulation of Pax6 and the onset of Crx expression were linked to departure from the cell cycle in photoreceptor progenitors. First, we pulse labeled the cultures with BrdU for 4 hours at day 0, cultured the cells for 1 and 2 more days in the absence of BrdU and analyzed Pax6 and Crx expression immediately after the pulse and after 1 or 2 days. Initially almost all (98\%) BrdU-positive cells expressed Pax6 (Fig. 5). This percentage decreased to $53 \%$ and $15 \%$ at days 1 and 2 in vitro, respectively (Figs. 5A-F, 5M). In contrast, Crx expression in BrdU labeled cells, which was almost negligible 4 hours after the cells were seeded, increased to $85 \%$ of BrdU labeled cells at day 2 (Figs. 5G-L, 5M). These results confirmed that Pax6 was expressed in most progenitor cells while they were still in the cell cycle. They also showed that most of the proliferating progenitor cells at day 0 eventually differentiated as photoreceptors, which lost Pax6 expression and massively began to express Crx. To confirm that Crx was expressed in postmitotic precursors, we pulse-labeled 0-, 1-, and 2-day cultures with BrdU for 4 hours and analyzed BrdU uptake and Crx expression immediately after the pulse. The amount of progenitors showing BrdU uptake markedly decreased during culture time. Whereas approximately $22 \%$ of retinal cells showed BrdU labeling after a 4 -hour pulse at day 0 , this labeling was reduced to only $4 \%$ of them by day 1 and practically disappeared by day 2 (Table 1), indicating that at this time in vitro virtually all cells had exited the cell cycle. On the contrary, Crx labeling increased during development from $30 \%$ to $70 \%$ of total cell number (Fig. 4E); $<2 \%$ of Crx-positive cells were labeled with BrdU after the pulse (Table 1) at every time analyzed, indicating that Crx was only expressed in postmitotic precursors.

\section{Incomplete Photoreceptor Differentiation in Crx-Expressing Cells}

Previous data have demonstrated that expression of Crx is essential for progenitor cells to become photoreceptors. ${ }^{12,15}$ Our present results show that downregulation of Pax6 expression and upregulation of Crx expression occurred in postmitotic precursors fated to become photoreceptors. In vivo, the onset of Crx expression led to the subsequent expression of opsin and to photoreceptor differentiation (Fig. 2). However, a similar developmental pattern did not occur in vitro. By day 3 , $92.5 \%$ of the retinal neurons in control cultures showing photoreceptor morphology expressed Crx (Table 2). Still, only 8000 cells/dish - that is, just $1.6 \%$ of the total photoreceptor cells, expressed opsin at day 3 in vitro (Fig. 6A) and this expression was widely distributed over the entire plasmalemma, both at this time and even at day 5 in vitro, as is observed in immature photoreceptors (Fig. 7E). Moreover, most Crx-positive cells in vitro lacked their characteristic outer segments, since only 6410 photoreceptors/dish (i.e., approximately $1.2 \%$ of these cells, had apical processes resembling the outer segment structures; Fig. 6B).

\section{DHA Effects on Crx-Positive Photoreceptors}

Because previous work had established that DHA enhanced photoreceptor differentiation, ${ }^{17,20}$ we first assessed whether this effect of DHA was related to its modulation of Crx expression. Analysis of this expression in cultures with or without DHA showed that the percentages of Crx-positive cells were similar in control and in DHA-treated cultures at days 3, 4, and 5 in vitro (Table 2). Hence, DHA did not seem to enhance Crx expression in photoreceptors.

Nevertheless, DHA supplementation improved all the markers of photoreceptor differentiation analyzed in every Crxpositive cell studied. In control cultures, the number of Crxpositive photoreceptors that coexpressed opsin was 8009 cells/dish at day 3 and increased to 22,853 and 24,540 cells/ dish at days 4 and 5, respectively (Fig. 6A). When the cultures were supplemented with DHA, the number of Crx-positive photoreceptors that expressed opsin remained at 11,909 cells/ dish at day 3 , but dramatically increased up to 48,344 and 44,246 cells/dish at days 4 and 5, respectively (Fig. 6A). Of note, in those few cases in which the cells expressed opsin but lacked Crx, these cells always showed fragmented or pyknotic nuclei (not shown).

In close correspondence with these findings, the number of Crx-positive photoreceptors having apical processes was significantly higher in DHA-supplemented cultures than in control cells (Fig 6B). In control cultures, the number of Crx-positive cells with apical processes was 6,410, 22,270, and 22,038 cells/dish, by days 3, 4, and 5, respectively. In DHA-treated cultures, this number remained similar to that in the control 
BrdU
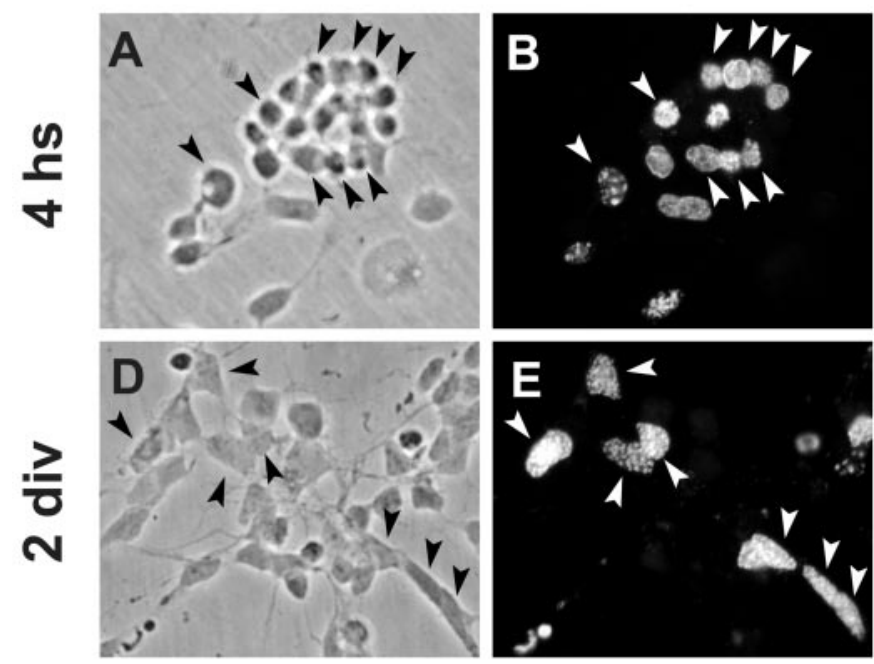

BrdU
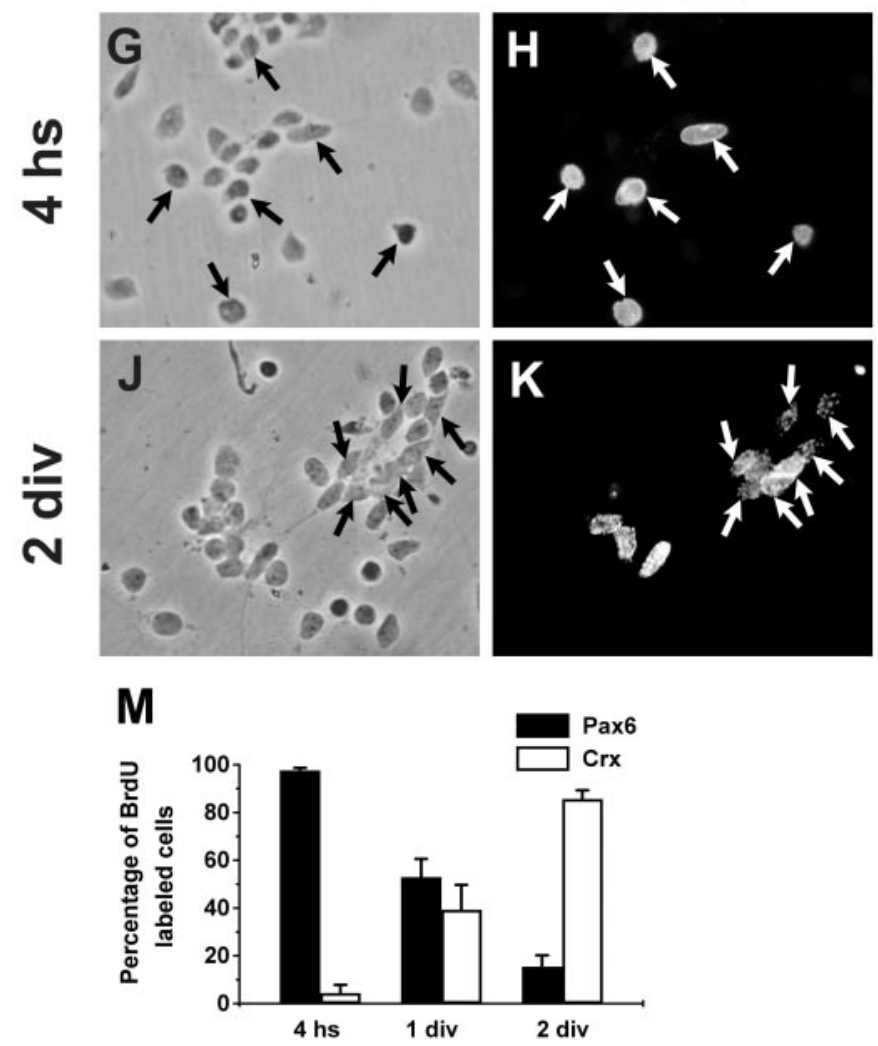

\section{Pax6}
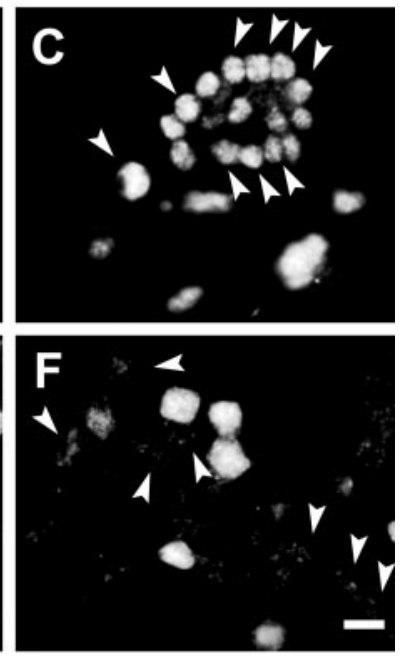

Crx
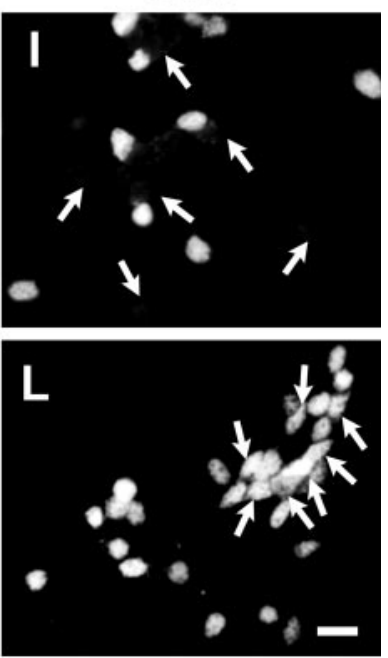

Figure 5. Timing of Crx and Pax6 expression in retinal progenitors in culture. Progenitor cells were pulse labeled with BrdU for 4 hours in vitro and subjected to BrdU and Pax6 (A-F) or BrdU and Crx (G-L) double immunostaining immediately after the pulse (A-C and $\mathbf{G}-\mathbf{I}), 1$ day later (not shown), or 2 days later (D-F and J-L). Immediately after the pulse, progenitor cells expressed Pax6 (A-C, arrowheads) but not Crx (G-I, arrows). Two days later, most postmitotic progenitors lost Pax6 expression (D-F, arrowheads) and began to express Crx (J-L). (M) Quantitative data of Pax6 and Crx expression in BrdU-labeled cells in vitro. Bar, $10 \mu \mathrm{m}$.

cultures at day 3 (i.e., 5260 cells/dish), but then remarkably increased up to 48,345 and 50,770 cells/dish at days 4 and 5, respectively (Fig. 6B). In day 5-control cultures, most photoreceptors were Crx-positive (Fig. 7C), but still lacked their characteristic outer segments (Figs. 7A, 7C, 7E), whereas conspicuous apical processes were observed in Crx-positive cells in DHA-treated cultures (Figs. 7B, 7D, 7F).

In addition, Crx-positive cells exhibited longer axons in DHA-treated than in control cultures (Fig. 7, arrowheads). Whereas in control cultures approximately $50 \%$ of Crx-positive cells had a short axon of approximately one cell diameter, in DHA-supplemented cultures, the major population of Crx-pos- itive cells exhibited longer axons, having a length of 2,3 , and 4 cell body diameters (Fig. $7 G$ ).

As a whole, these results suggest that DHA did not affect Crx expression in progenitor cells. Instead, its interaction with Crx-positive cells was essential to continue their differentiation as photoreceptors after 3 days in vitro-that is, once they had reached a certain stage of differentiation.

\section{Discussion}

Three major conclusions can be drawn from this work: first, Pax6 expression occurred in most progenitor cells while they pro- 
TABLE 1. BrdU Incorporation in Total and Crx-Positive Cells

\begin{tabular}{ccc}
\hline Days In Vitro & $\begin{array}{c}\text { BrdU/Total Cell } \\
\text { Number (\%) }\end{array}$ & BrdU-Crx/Crx (\%) \\
\hline 0 & $21.7 \pm 4.4$ & $2.0 \pm 1.4$ \\
1 & $3.8 \pm 1.8$ & $0.8 \pm 0.2$ \\
2 & $0.1 \pm 0.0 *$ & $0.0 \pm 0.0 \dagger$
\end{tabular}

Retinal cell cultures from P0 retinas were pulse labeled with BrdU for 4 hours at days 0,1 , and 2 in vitro, fixed after the pulse, and subjected to immunocytochemistry to detect BrdU incorporation and Crx expression. Data are the mean \pm SD of results in three separate experiments. At least three culture dishes were used for each experiment.

$* 0.1 \% \pm 0.02 \%$.

† Less than $0.01 \%$.

gressed in the cell cycle during early eye and retina development. Second, immediately after finishing their last mitotic division, photoreceptor precursors stopped expressing Pax6 and began expressing Crx, one of the earliest hallmarks of photoreceptor differentiation; and third, Crx expression was not sufficient to achieve complete differentiation of photoreceptors, a task that demanded, at least, the contribution of DHA.

\section{Early Expression of Pax6 in Cycling Progenitor Cells}

The development and differentiation of rod photoreceptors require the sequential participation of two key transcription factors in the retina, Pax6 and Crx. Pax6 is essential for eye development and is well established as an eye determinant ${ }^{38}$; however, the molecular processes it regulates to induce progenitor cells to become an eye remain ill-defined. Pax6 has a DNA binding domain that affects cell proliferation in the developing brain and has been shown to regulate the cell cycle in cortical progenitors, whereas Pax6 mutant mice have a reduced proliferation in their optic vesicle. ${ }^{39-41}$ During the early stages of development in the prospective retina, it is absolutely essential for progenitor cells to remain in the cell cycle until the required number of cells is reached. Since Pax6 expression is activated in progenitor cells throughout their whole proliferation period and is switched off in photoreceptor progenitors as soon as they stop proliferating, it may participate in the regulation of cell cycle progression. Our present results consistently support this hypothesis. Both in vivo and in vitro experiments showed that Pax6 expression was parallel to BrdU uptake and in vitro experiments showed that retinal progenitors coexpressed Pax 6 and nestin, while progressing in the cell cycle. Pax6 expression closely corresponded with an effective mitotic activity in progenitor cells. Altogether, these results support previous data suggesting that Pax6 may be involved in regulating cell cycle progression in retina progenitors.

Table 2. Percentage of Photoreceptors Expressing Crx

\begin{tabular}{ccc}
\hline Days In Vitro & Control & DHA \\
\hline 3 & $92.5 \pm 2.2$ & $93.0 \pm 0.6$ \\
4 & $93.6 \pm 3.0$ & $94.1 \pm 1.5$ \\
5 & $93.8 \pm 2.1$ & $94.0 \pm 2.3$ \\
\hline
\end{tabular}

Retinal neurons were cultured in the absence or presence of DHA, and the percentage of photoreceptors that expressed Crx was quantified at 3,4 , and 5 days in vitro. Data are the mean \pm SD of results in four separate experiments. At least three culture dishes were used for each experiment.

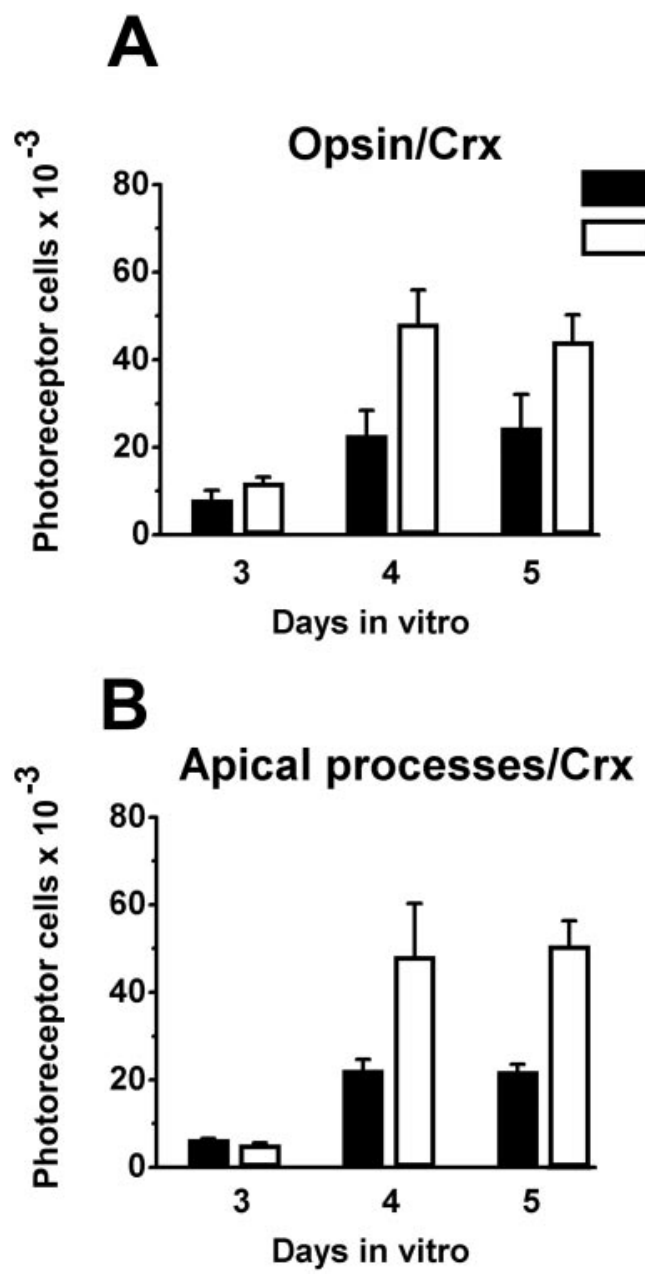

FiguRE 6. DHA's effect on photoreceptor differentiation. The number of photoreceptors that expressed Crx and either expressed opsin or had apical processes was analyzed in cultures of 3 to 5 days in vitro without or with the addition of DHA. Addition of DHA induced further differentiation on photoreceptors that already expressed Crx.

\section{The Switch from Pax6 to Crx during Photoreceptor Differentiation}

At early stages of development, Pax6 expression was observed in both amacrine and photoreceptor progenitors; however, its expression was excluded from photoreceptors once they became postmitotic. In vitro and in vivo experiments showed that as soon as photoreceptor progenitors departed the cell cycle, they switched off Pax6 expression and massively began to express Crx, the photoreceptor-specific transcription factor essential for establishing a photoreceptor fate. ${ }^{11,12}$ In the retina in vivo, Crx occurred only in the prospective outer nuclear layer, and only in those cells in which Pax6 expression had already disappeared (Fig. 2). Specifically, overexpression of Pax6 has been reported to lead to the development of fewer photoreceptors. ${ }^{42}$ The onset of Crx expression preceded that of opsin, as has been previously reported. ${ }^{43}$ The pattern of Crx expression was similar to that described in the mouse retina at similar developmental stages, where it was weak by E20 and P0 in the outer layer of the neuronal retina and then increased in the prospective photoreceptor layer by $\mathrm{P} 3$ to $\mathrm{P} 6 .^{11,12,44,45}$ In vivo and in vitro experiments showed that Crx was only ex- 

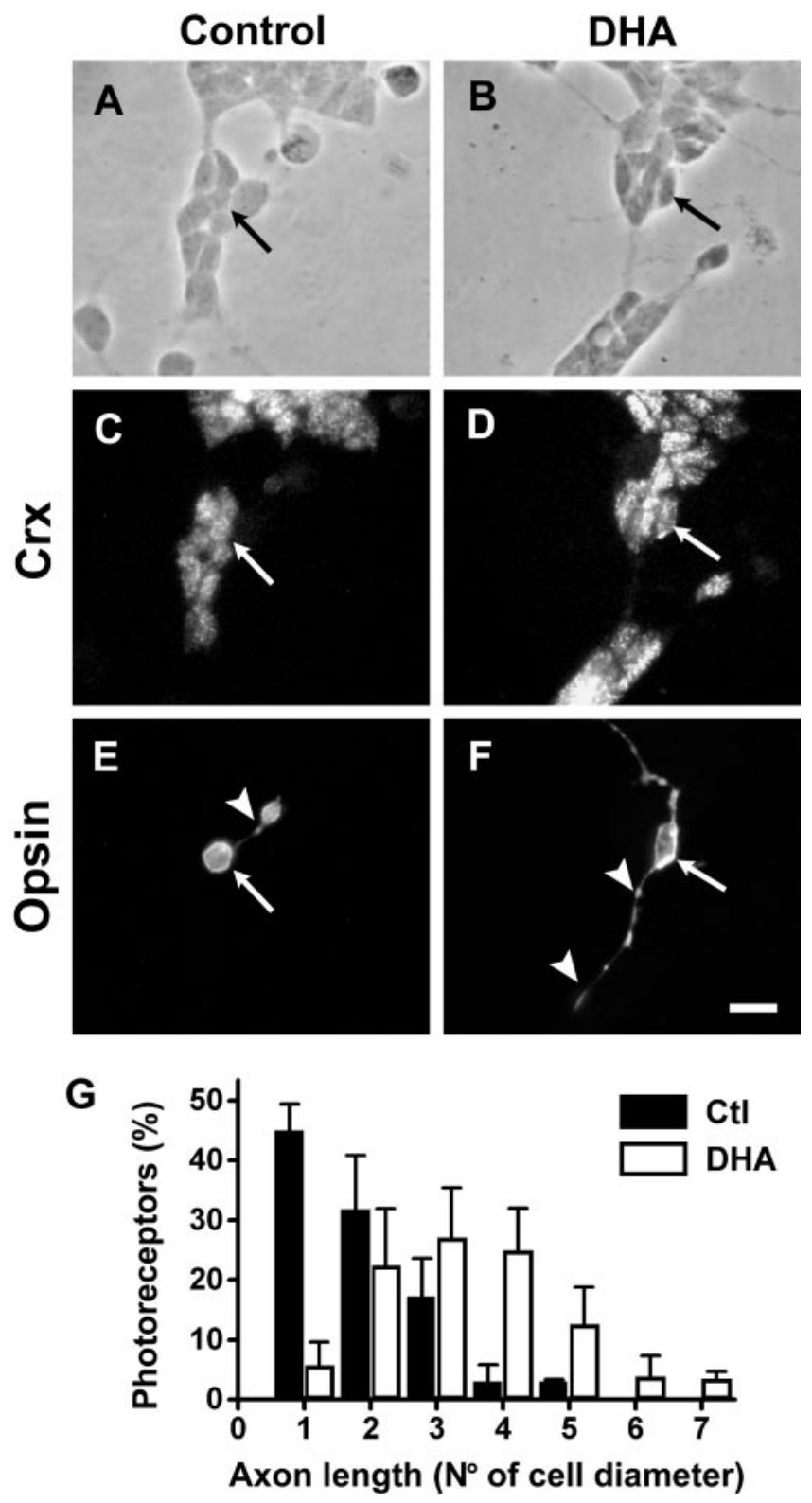

FIGURE 7. Effects of DHA in neurite outgrowth in Crx-positive photoreceptors. Five-day in vitro cultures without $(\mathbf{A}, \mathbf{C}, \mathbf{E})$ or with the addition of DHA (B, D, F) showing Crx (C, D) and opsin immunolocalization (E, F). Neurite length $(\mathbf{G})$ was measured as the number of cell diameters, in 4-day cultures without or with DHA. After addition of DHA, photoreceptor cells developed longer neurites. Bar, $10 \mu \mathrm{m}$.

pressed in cells in which BrdU incorporation, and hence the capability to proliferate were already absent.

Crx appears to be indispensable for photoreceptor development. In the few cases in which photoreceptors expressed opsin but lacked Crx, their nuclei were always fragmented or pyknotic. This indicates that these cells were rapidly progressing in a degenerative pathway, and is consistent with the finding that mutations in the Crx gene lead to the degeneration of photoreceptors. ${ }^{13,14}$

Altogether, these results suggest that photoreceptors may initially require the expression of Pax6 to regulate their proliferation and that disappearance of this expression precedes the onset of their differentiation, a process that requires activation of Crx expression.

\section{DHA as a Molecular Cue for Promoting Photoreceptor Differentiation}

In the retina in vivo, the onset of Crx expression preceded the beginning of opsin expression, which concurred with Crx expression later in development (Fig. 2). These results agree with previous reports relating Crx expression to photoreceptor differentiation. ${ }^{11,12}$ They also support the model that suggests that specification of photoreceptor fate involves a sequence of developmentally regulated steps. ${ }^{11}$

The pattern of development was different in vitro. During the first 2 days in vitro, almost all cells having a photoreceptor morphology started to express Crx. This suggests that either the signals required for the activation of this expression were present in the culture medium or, more probably, that these cells had already received the cues for the induction of Crx expression while they were still in the embryonic retina. In any case, the onset of Crx expression allowed them to initiate their differentiation as photoreceptors. However, the close initial association between the expression of Crx and photoreceptor morphology did not correspond with the progression to an advanced stage of differentiation in these cells. Hence, Crx expression alone was not sufficient to steer photoreceptor differentiation in vitro. Previous work has determined that photoreceptor progenitors require several transcription factors to proceed with the differentiation pathway, including $\mathrm{Nrl}$, NeuroD, and $\mathrm{Nr} 2 \mathrm{e} 3{ }^{3,4,16,46}$ as well as environmental cues such as taurine, ${ }^{47}$ basic fibroblast growth factor, ${ }^{48}$ and glial cell line-derived neurotrophic factor. ${ }^{18}$ We have previously shown that DHA promotes photoreceptor differentiation in vitro. ${ }^{17,20,23}$ Our present results evidenced that DHA did not influence Crx expression in photoreceptor progenitors to achieve this effect. This finding implies that photoreceptor fating was independent of DHA. In contrast, DHA had a key role in enhancing photoreceptor differentiation in Crx-expressing cells, which were already committed to differentiation as photoreceptors. In these cells, DHA markedly promoted opsin expression, apical differentiation and axonal outgrowth, an improvement in their differentiation that required that photoreceptors had already developed for 4 days in vitro (Figs. 6, 7), consistent with the previously observed delay between terminal mitosis in rod photoreceptor progenitors and the onset of rhodopsin expression. ${ }^{37}$ Hence, DHA did not alter Crx expression; conversely, the onset of Crx expression allowed photoreceptors to reach a permissive stage in their development at which they became responsive to DHA and needed it to advance in their differentiation.

An intriguing question is how DHA achieves these effects. It has been established that DHA is a natural and specific ligand that induces activation of retinoid orphan receptors in mouse brain. ${ }^{49,50}$ By binding to these receptors, which are heterodimer partners for other nuclear receptors, DHA may regulate gene expression. Moreover, DHA has been shown to regulate transcription of several genes in fetal explants from human retina. ${ }^{51}$ It can then be hypothesized that DHA may increase opsin expression by a similar mechanism. An alternative explanation may be the activation by DHA of signaling pathways usually involved in promoting cell survival and differentiation, such as the extracellular signal regulated kinase (ERK) or the phosphatidylinositol-3-kinase pathway. In addition, as a critical outer segment constituent, DHA may improve disc and outer segment biogenesis. Rhodopsin has been shown to associate with DHA-containing phospholipids in the transGolgi network and then remain closely associated during migration throughout photoreceptor outer segments. ${ }^{52,53}$ DHA addition to the culture medium prompts its concentration in photoreceptor apical processes, ${ }^{24}$ and a rapid increase in its 
content in neuronal lipids. ${ }^{49,50}$ Hence, DHA may enhance opsin expression and simultaneously provide the DHA-containing phospholipids required for building these membranes, thus allowing the development of apical processes. The involvement of these pathways in photoreceptor differentiation remains to be established.

There is a growing consensus now that developing photoreceptors require the participation of several trophic factors for their survival and differentiation, such as bFGF and glialderived neurotrophic factor (GDNF). ${ }^{18,54}$ These results strongly suggest that DHA is also a critical molecular cue, essential for photoreceptor development and differentiation. The onset of Crx expression seems to be associated to the potential to develop a photoreceptor identity rather than to the acquisition of specific differentiated photoreceptor features. The acquisition of these features requires of the combined or sequential involvement of intrinsic and extrinsic factors, among which the contribution of DHA is undoubtedly essential to develop differentiated, functional photoreceptors.

\section{Acknowledgment}

The authors thank Elisa B. de los Santos for her excellent technical assistance and Horacio V. Maturi and Marita Carranza for their help in the preparation of cryosections.

\section{References}

1. Cepko CL, Austin CP, Yang X, Alexiades M, Ezzeddine D. Cell fate determination in the vertebrate retina. Proc Natl Acad Sci USA. 1996;93:589-595.

2. Hill RE, Favor J, Hogan BL, et al. Mouse small eye results from mutations in a paired-like homeobox-containing gene. Nature. 1991;354:522-525.

3. Cheng H, Khanna H, Oh EC, Hicks D, Mitton KP, Swaroop A. Photoreceptor-specific nuclear receptor NR2E3 functions as a transcriptional activator in rod photoreceptors. Hum Mol Genet. 2004; 13:1563-1575.

4. Mears AJ, Kondo M, Swain PK, et al. Nrl is required for rod photoreceptor development. Nat Genet. 2001;29:447-452.

5. Akagi T, Mandai M, Ooto S, et al. Otx2 homeobox gene induces photoreceptor-specific phenotypes in cells derived from adult iris and ciliary tissue. Invest Ophthalmol Vis Sci. 2004;45:4570-4575.

6. Hanson IM, Fletcher JM, Jordan T, et al. Mutations at the PAX6 locus are found in heterogeneous anterior segment malformations including Peters' anomaly. Nat Genet. 1994;6:168-173.

7. Glaser T, Walton DS, Cai J, Epstein JA, Jepeal L, Maas RL. PAX6 gene mutations in aniridia. In: Wiggs JL, ed. Molecular Genetics of Ocular Disease. New York: Wiley-Liss; 1995:51-82.

8. Glaser T, Jepeal L, Edwards JG, Young SR, Favor J, Maas RL. PAX6 gene dosage effect in a family with congenital cataracts, aniridia, anophthalmia and central nervous system defects. Nat Genet. 1994;7:463-471.

9. Kawakami A, Kimura-Kawakami M, Nomura T, Fujisawa H. Distributions of PAX6 and PAX7 proteins suggest their involvement in both early and late phases of chick brain development. Mech Dev. 1997;66:119-130.

10. Marquardt T, Gruss P. Generating neuronal diversity in the retina: one for nearly all. Trends Neurosci. 2002;25:32-38.

11. Chen S, Wang QL, Nie Z, et al. Crx, a novel Otx-like pairedhomeodomain protein, binds to and transactivates photoreceptor cell-specific genes. Neuron. 1997;19:1017-1030.

12. Furukawa T, Morrow EM, Cepko CL. Crx, a novel otx-like homeobox gene, shows photoreceptor-specific expression and regulates photoreceptor differentiation. Cell. 1997;91:531-541.

13. Freund CL, Gregory-Evans CY, Furukawa T, et al. Cone-rod dystrophy due to mutations in a novel photoreceptor-specific homeobox gene (CRX) essential for maintenance of the photoreceptor. Cell. 1997;91:543-553.
14. Rivolta C, Berson EL, Dryja TP. Dominant Leber congenital amaurosis, cone-rod degeneration, and retinitis pigmentosa caused by mutant versions of the transcription factor CRX. Hum Mutat. 2001;18:488-498.

15. Furukawa T, Morrow EM, Li T, Davis FC, Cepko CL. Retinopathy and attenuated circadian entrainment in Crx-deficient mice. Nat Genet. 1999;23:466-470.

16. Akagi T, Akita J, Haruta M, et al. Iris-derived cells from adult rodents and primates adopt photoreceptor-specific phenotypes. Invest Ophthalmol Vis Sci. 2005;46:3411-3419.

17. Rotstein NP, Aveldano MI, Barrantes FJ, Politi LE. Docosahexaenoic acid is required for the survival of rat retinal photoreceptors in vitro. J Neurochem. 1996;66:1851-1859.

18. Politi LE, Rotstein NP, Carri NG. Effect of GDNF on neuroblast proliferation and photoreceptor survival: additive protection with docosahexaenoic acid. Invest Opbthalmol Vis Sci. 2001;42:3008-3015.

19. Rotstein NP, Aveldano MI, Barrantes FJ, Roccamo AM, Politi LE. Apoptosis of retinal photoreceptors during development in vitro: protective effect of docosahexaenoic acid. J Neurochem. 1997;69: 504-513.

20. Rotstein NP, Politi LE, Aveldano MI. Docosahexaenoic acid promotes differentiation of developing photoreceptors in culture. Invest Ophthalmol Vis Sci. 1998;39:2750-2758.

21. Rotstein NP, Politi LE, German OL, Girotti R. Protective effect of docosahexaenoic acid on oxidative stress-induced apoptosis of retina photoreceptors. Invest Opbthalmol Vis Sci. 2003;44:22522259.

22. Mitchell DC, Niu SL, Litman BJ. Enhancement of G protein-coupled signaling by DHA phospholipids. Lipids. 2003;38:437-443.

23. Insua MF, Garelli A, Rotstein NP, German OL, Arias A, Politi LE. Cell cycle regulation in retinal progenitors by glia-derived neurotrophic factor and docosahexaenoic acid. Invest Opbthalmol Vis Sci. 2003;44:2235-2244.

24. Politi LE, Rotstein N, Carri N. Effects of docosahexaenoic acid on retinal development: cellular and molecular aspects. Lipids. 2001; 36:927-935.

25. Bobrow MN, Shaughnessy KJ, Litt GJ. Catalyzed reporter deposition, a novel method of signal amplification. II. Application to membrane immunoassays. J Immunol Metbods. 1991;137:103112.

26. Davis JA, Reed RR. Role of Olf- 1 and Pax-6 transcription factors in neurodevelopment. J Neurosci. 1996;16:5082-5094.

27. Mastick GS, Davis NM, Andrew GL, Easter SS Jr. Pax-6 functions in boundary formation and axon guidance in the embryonic mouse forebrain. Development. 1997;124:1985-1997.

28. Zhu X, Craft CM. Modulation of CRX transactivation activity by phosducin isoforms. Mol Cell Biol. 2000;20:5216-5226.

29. Laird DW, Molday RS. Evidence against the role of rhodopsin in rod outer segment binding to RPE cells. Invest Ophthalmol Vis Sci. 1988;29:419-428.

30. Politi LE, Bouzat C, los Santos EB, Barrantes FJ. Heterologous retinal cultured neurons and cell adhesion molecules induce clustering of acetylcholine receptors and polynucleation in mouse muscle BC3H-1 clonal cell line. J Neurosci Res. 1996;43:639-651.

31. Rapaport DH, Wong LL, Wood ED, Yasumura D, LaVail MM. Timing and topography of cell genesis in the rat retina.J Comp Neurol. 2004; 474:304-324.

32. Adler R. Regulation of neurite growth in purified retina neuronal cultures: effects of PNPF, a substratum-bound, neurite-promoting factor. J Neurosci Res. 1982;8:165-177.

33. Hicks D, Barnstable CJ. Different rhodopsin monoclonal antibodies reveal different binding patterns on developing and adult rat retina. J Histochem Cytochem. 1987;35:1317-1328.

34. Marquardt T, Ashery-Padan R, Andrejewski N, Scardigli R, Guillemot F, Gruss P. Pax6 is required for the multipotent state of retinal progenitor cells. Cell. 2001;105:43-55.

35. Morrow EM, Furukawa T, Cepko CL. Vertebrate photoreceptor cell development and disease. Trends Cell Biol. 1998;8:353-358.

36. Rhee KD, Goureau O, Chen S, Yang XJ. Cytokine-induced activation of signal transducer and activator of transcription in photore- 
ceptor precursors regulates rod differentiation in the developing mouse retina. $J$ Neurosci. 2004;24:9779-9788.

37. Kammandel B, Chowdhury K, Stoykova A, Aparicio S, Brenner S, Gruss P. Distinct cis-essential modules direct the time-space pattern of the Pax6 gene activity. Dev Biol. 1999;205:79-97.

38. Gehring WJ, Ikeo K. Pax 6: mastering eye morphogenesis and eye evolution. Trends Genet. 1999;15:371-377.

39. Haubst N, Berger J, Radjendirane V, et al. Molecular dissection of Pax6 function: the specific roles of the paired domain and homeodomain in brain development. Development. 2004;131:61316140.

40. Estivill-Torrus G, Pearson H, van Heyningen V, Price DJ, Rashbass P. Pax6 is required to regulate the cell cycle and the rate of progression from symmetrical to asymmetrical division in mammalian cortical progenitors. Development. 2002;129:455-466.

41. Philips GT, Stair CN, Young LH, et al. Precocious retinal neurons: Pax6 controls timing of differentiation and determination of cell type. Dev Biol. 2005;279:308-321.

42. Toy J, Norton JS, Jibodh SR, Adler R. Effects of homeobox genes on the differentiation of photoreceptor and nonphotoreceptor neurons. Invest Ophthalmol Vis Sci. 2002;43:3522-3529.

43. Morrow EM, Belliveau MJ, Cepko CL. Two phases of rod photoreceptor differentiation during rat retinal development. J Neurosci. 1998; $18: 3738-3748$.

44. Furukawa A, Koike C, Lippincott P, Cepko CL, Furukawa T. The mouse Crx $5^{\prime}$-upstream transgene sequence directs cell-specific and developmentally regulated expression in retinal photoreceptor cells. J Neurosci. 2002;22:1640-1647.

45. Bibb LC, Holt JK, Tarttelin EE, et al. Temporal and spatial expression patterns of the CRX transcription factor and its downstream targets: critical differences during human and mouse eye development. Hum Mol Genet. 2001;10:1571-1579.

46. Mitton KP, Swain PK, Chen S, Xu S, Zack DJ, Swaroop A. The leucine zipper of NRL interacts with the CRX homeodomain: a possible mechanism of transcriptional synergy in rhodopsin regulation. J Biol Chem. 2000;275:29794-29799.

47. Altshuler D, Lo Turco JJ, Rush J, Cepko C. Taurine promotes the differentiation of a vertebrate retinal cell type in vitro. Development. 1993;119:1317-1328.

48. Hicks D, Courtois Y. Fibroblast growth factor stimulates photoreceptor differentiation in vitro. J Neurosci. 1992;12:2022-2033.

49. Lengqvist J, Mata DU, Bergman AC, et al. Polyunsaturated fatty acids including docosahexaenoic and arachidonic acid bind to the retinoid X receptor alpha ligand-binding domain. Mol Cell Proteom. 2004;3:692-703.

50. Mata de Urquiza A, Liu S, Sjoberg M, et al. Docosahexaenoic acid, a ligand for the retinoid $\mathrm{X}$ receptor in mouse brain. Science. 2000;290:2140-2144.

51. Rojas CV, Martinez JI, Flores I, Hoffman DR, Uauy R. Gene expression analysis in human fetal retinal explants treated with docosahexaenoic acid. Invest Ophthalmol Vis Sci. 2003;44:3170-3177.

52. Gordon WC, Bazan NG. Docosahexaenoic acid utilization during rod photoreceptor cell renewal. J Neurosci. 1990;10:2190 2202.

53. Rodriguez de Turco EB, Deretic D, Bazan NG, Papermaster DS. Post-Golgi vesicles cotransport docosahexaenoyl-phospholipids and rhodopsin during frog photoreceptor membrane biogenesis. J Biol Chem. 1997;272:10491-10497.

54. Fontaine V, Kinkl N, Sahel J, Dreyfus H, Hicks D. Survival of purified rat photoreceptors in vitro is stimulated directly by fibroblast growth factor-2. J Neurosci. 1998;18:9662-9672. 